\title{
A reciclagem de sucata eletrônica como tema gerador de práticas educativas no nível médio do Ensino de Química
}

\section{The recycling of electronic scrap as generative theme of educational practices at the High School level of Chemistry Teaching}

\author{
Vanda Thomas Preussler (vanda.thomas@ hotmail.com) \\ Professora de Química do Ensino Médio em Escolas Estaduais de Educação Básica do RS, Brasil. \\ Especialista em Orientação Educacional.
}

Patrícia Marasca Fucks (arquiteturis@yahoo.com.br)

Professora do Magistério Superior e pesquisadora da Universidade Federal da Fronteira Sul (UFFS), Campus Cerro Largo, RS, Brasil. Doutora em Educação Científica e Tecnológica.

Resumo: A crescente produção brasileira de lixo eletrônico e sua destinação inadequada prejudicam o Meio Ambiente e bem-estar. No contexto escolar, enfocando-se a Educação Ambiental, discute-se a problematização dessa realidade: Como a temática da reciclagem de sucata eletrônica é utilizada nas práticas educativas em aula, no nível médio do Ensino de Química, para sensibilização ambiental discente? Objetivou-se analisar possibilidades de uso da reciclagem de sucata eletrônica como tema gerador das práticas educativas no nível médio do Ensino de Química. Com abordagem qualitativa, desenvolveu-se a Pesquisa Bibliográfica, consultando-se publicações em acesso aberto para constituição do corpus de análise. A perspectiva freireana norteou o percurso teórico-metodológico, interpretando-se os dados pela Análise Textual Discursiva. Constatou-se preponderância de atividades (aulas teóricas, gincanas e palestras) concebidas isoladamente, desarticuladas do ensino praticado e dos demais conteúdos curriculares. Resultaram categorizadas, como Estratégias Didáticas, duas possibilidades de abordagem da questão socioambiental: o uso de Experimentação e de Histórias em Quadrinhos. Elas provocaram reflexões, no plano social e pedagógico, sobre como conduzir dialeticamente o desenvolvimento de práticas educativas inovadoras, a partir do tema gerador. Desafiaram docentes a compartilhar saberes e relatar suas experiências, repensando o ensinar, em favor da formação cidadã comprometida com a questão socioambiental, oportunizando uma Educação transformadora.

Palavras-chave: Lixo eletrônico; Resíduo Sólido; Educação Ambiental.

Abstract: The increasing production of electronic waste in Brazil and its inadequate destination harm the environment and the well-being. In the school context, focusing the Environmental Education, the problematics of the following reality is discussed: How is the electronic scrap recycling theme used in the educational practices in class, at the High School level of Chemistry Teaching, for student environmental awareness? It was aimed to analyze the possibilities of using recycling of electronic scrap as generative theme of educational practices at the High School level of Chemistry Teaching. With a qualitative approach, a Bibliographic Research was carried out, consulting open access publications for the constitution of the analysis corpus. The Freire's perspective guided the theoretical- 
methodological path, interpreting the data by the Discursive Textual Analysis. A preponderance of activities (theoretical classes, gymkhanas and lectures) conceived in isolation, disconnected from the practiced teaching and from the other curricular contents was observed. As a result, two categorized possibilities of Didactic Strategies were found for approaching the socio-environmental issue: Experimentation and Comics. They provoked reflection, in the social and pedagogical plane, on how to conduct dialectically the development of innovative educational practices, starting from the generative theme. And they challenged teachers to share knowledge and report their experiences, rethinking teaching, in favor of the citizen formation committed to the socio-environmental issue, for a transforming Education.

Keywords: Electronic waste; Solid waste; Environmental Education.

\section{INTRODUÇÃO}

A crescente preocupação com as questões socioambientais, imbricadas ao gerenciamento dos resíduos sólidos, é uma discussão pertinente e cuja compreensão pode ser abarcada pela Educação Ambiental, pela abordagem dos estudos em Ciência, Tecnologia e Sociedade (CTS) e pelas ideias de Freire (1987).

O gerenciamento dos resíduos sólidos abarca um conjunto de ações ou medidas, exercidas direta ou indiretamente, e várias etapas regulamentadas pela Política Nacional de Resíduos Sólidos (PNRS). Sua aplicação busca reduzir a produção desse tipo de resíduos, proporcionar sua coleta, armazenamento, tratamento, transporte e destinação final adequada (BRASIL, 2010).

O interesse e mobilização das pessoas em participar ou não desse processo, acaba por refletir o seu grau de sensibilização em relação à conservação do meio ambiente e de outros bens da coletividade. Revela, ainda, os conhecimentos e valores sociais construídos, as habilidades e competências desenvolvidas em seu processo formativoeducativo, no qual se evidencia o papel da Educação Ambiental. Conforme a Resolução CNE/CP no 2, de 15/06/20, a "Educação Ambiental é uma dimensão da educação, é atividade intencional da prática social” (BRASIL, 2012).

Na contemporaneidade, a tecnologia está cada vez mais incorporada à rotina e aos hábitos de vida da população e a frequência de sua utilização tem estado proeminente diante das necessidades de distanciamento social, que surgiram no contexto da pandemia do coronavírus. São mudanças que têm demandado o uso de Equipamentos 
Eletroeletrônicos (EEE) diversos, viabilizando atividades de caráter educativo, assistencial, econômico, social e/ou cultural, com a implementação crescente de home office, e-commerce, internet banking, tele-atendimento, educação à distância, ensino remoto, interação virtual, entre outras.

A problematização dessa realidade na Educação escolar suscita questionamentos por parte dos professores, nos quais cabe ponderar discutindo sobre o ônus e o bônus ao meio ambiente e à saúde humana, decorrentes do emprego indiscriminado da tecnologia. Compete alertar para as possíveis dificuldades de ordem comportamental, sociocultural e psicofisiológica que podem ser geradas aos usuários, induzindo-os a uma sensação de dependência dos benefícios da tecnologia. Quanto à saúde, pode repercutir em esgotamento físico e mental, na criação de falsas necessidades (consumo de supérfluos), com tendência a acentuar aspectos relacionados ao consumismo, isolamento social, aos quadros depressivos e de ansiedade.

Com a frequência de uso e velocidade com que as tecnologias têm avançado, importa estimular os alunos a pensar de forma crítica, posicionar-se ética e politicamente sobre o assunto. E, assim, fazê-los refletir sobre o montante considerável de Resíduos de Equipamento Eletroeletrônicos (REEE) e suas respectivas embalagens que têm sido geradas e descartadas pela sociedade, mas que precisam de uma destinação correta, inclusive exigida por lei.

O problema socioambiental associado à degradação das condições do solo, da qualidade da água e do ar, tende a agravar-se como consequência do descarte irresponsável e em locais inapropriados do 'lixo eletrônico'. Esse termo refere-se a qualquer REEE, o qual precisa de uma 'destinação correta', juntamente com suas respectivas embalagens, conforme exigências da Lei nº 12.305, de 02/08/2010 (BRASIL, 2010). Por meio desse instrumento legal, a gestão de resíduos deve garantir o máximo de reaproveitamento e reciclagem e a minimização dos rejeitos.

Com base na referida Lei, o 'lixo eletrônico’ enquadra-se como um resíduo sólido, oriundo de domicílios ou estabelecimentos comerciais e prestadores de serviços, e que pode ser classificado como resíduo perigoso. Além disso, no seu Art.33, inciso VI, está explicitada a exigência da implementação de Sistemas de Logística Reversa. Isso significa que também os fabricantes, importadores, distribuidores e comerciantes de 
produtos eletroeletrônicos e seus componentes "são obrigados a estruturar e implementar sistemas de logística reversa, mediante retorno dos produtos após o uso pelo consumidor, de forma independente do serviço público de limpeza urbana e de manejo dos resíduos sólidos" (BRASIL, 2010, p.16).

Apropriando-se de tais conhecimentos, tem-se um ponto de partida e um indicativo de caminhos que podem conduzir os professores à problematização desse assunto no contexto educacional, tanto da Escola quanto da Universidade. O 'lixo eletrônico' é temática que precisa ser problematizada, aproximando-a à realidade dos alunos e aos seus conhecimentos prévios para que os aprendizados possam ser efetivos e ressignificados. E, assim, tornar os alunos aptos a transformar as informações (dados) a que eles têm acesso em conhecimentos e, estes, em habilidades.

No trabalho, essa discussão é encaminhada pelo viés da perspectiva teórica freireana, refletindo-se sobre práticas educativas com temas geradores, como a reciclagem de sucata eletrônica. Com foco na Educação Ambiental escolar, o assunto foi assim problematizado: Como a temática da reciclagem de sucata eletrônica está sendo utilizada nas práticas educativas, no nível Médio do Ensino de Química, para sensibilização ambiental dos alunos?

O estudo teve como objetivo analisar possibilidades de uso da reciclagem de sucata eletrônica como tema gerador das práticas educativas no nível médio do Ensino de Química. Buscou-se uma aproximação das discussões do artigo refletindo sobre suas aplicações à realidade da Educação Escolar de Caibaté/RS, no Noroeste gaúcho. Com população estimada em 4.954 pessoas, em uma área territorial de $A=261,303 \mathrm{~km}^{2}$ (IBGE, 2019), o município possui apenas um estabelecimento público de ensino médio, a Escola Estadual de Educação Básica José Adolfo Meister que, em 2020, contou com 113 alunos matriculados nesta modalidade de ensino, nos turnos da manhã e noite.

Muitas ideias e inquietações trazidas à luz neste estudo decorrem da vivência de uma das autoras, cuja atuação como professora de Química do ensino médio diurno é em Escolas da região das Missões, no Noroeste gaúcho. Os questionamentos refletem a angústia em relação às possibilidades de compreensão e constituição do aprendizado dos alunos, partindo-se da discussão em aula sobre a crescente demanda envolvendo a 
produção e o consumo de EEE, o descarte de seus resíduos e a questão da reciclagem do lixo eletrônico.

Para atingir o propósito do trabalho, por intermédio da Pesquisa Bibliográfica, sucederam as etapas descritas na seção subsequente.

\section{METODOLOGIA}

O estudo desenvolvido, no que tange à sua abordagem, possui natureza qualitativa (GIL, 2002, 2008). Quanto aos procedimentos e delineamento, seus dados foram obtidos por meio da Pesquisa Bibliográfica sobre reciclagem de sucata eletrônica, focando questões da Educação Ambiental e das práticas educativas a partir de temas geradores no Ensino Médio.

Procedeu-se, inicialmente, com a consulta a vocabulários controlados como o Vocabulário Controlado da USP (UNIVERSIDADE DE SÃO PAULO) e o Thesaurus Brasileiro da Educação (Brased), do Instituto Nacional de Estudos e Pesquisas Educacionais Anísio Teixeira (INEP). Essa consulta apontou descritores ou termos relevantes ao estudo como resíduos sólidos; reciclagem; sucata eletrônica; lixo eletrônico; Educação Ambiental.

Esses termos relevantes auxiliaram posteriormente na construção da expressão de busca que foi aplicada a 'bases de dados bibliográficos', como o Scientific Eletronic Library Online (SCIELO.ORG), e 'buscadores' como o Google Schoolar (Google Acadêmico) e o Open Access and Scholarly Information System (OASIS.BR) - Portal Brasileiro de Publicações Científicas, dispostos em acesso aberto. Essas fontes de informações caracterizam-se pela sua disponibilidade on-line, acesso gratuito e integral ao conteúdo dos resultados oriundos de investigações científicas. Elas foram usadas na constituição do corpus de análise permitiram consultar publicações em acesso aberto, de instituições de ensino público e privado do Brasil, tais como artigos de periódicos ou anais de eventos, livros, capítulos de livro, trabalhos monográficos, e-books. 
Nesses materiais publicados em língua portuguesa foram pré-selecionados, para posterior leitura e análise, aqueles que contivessem, no seu título, resumo e/ou nas palavras-chave os termos previamente identificados como relevantes à pesquisa, considerando-se as publicações dos últimos cinco anos. Sendo assim, o corpus da pesquisa estruturou-se na análise desse material bibliográfico, o qual constituiu a base para descrição e compreensão do problema investigado.

O percurso teórico-metodológico foi balizado nas ideias de Freire (1987), o qual defende que a Educação que se pretende transformadora e conscientizadora deve organizar o conteúdo programático elegendo temas advindos da situação de vida presente, existencial e concreta dos sujeitos (situados temporal e espacialmente no seu tempo), como discute Corazza (2003).

Com o corpus definido, partiu-se para a análise e interpretação dos dados seguindo a metodologia da Análise Textual Discursiva (ATD), segundo Moraes e Galiazzi (2007). A ATD consiste na análise e desmontagem de textos e discursos para produção de novas compreensões, captação e comunicação do novo emergente. Foram executadas as etapas descritas por Moraes (2003), que incluíram a unitarização, o processo de categorização e o metatexto.

Conforme Sousa e Galiazzi (2018), a categorização representa um esforço de construção de sistemas de categorias com as novas aprendizagens que se originaram do metatexto. O metatexto constitui-se da comunicação e validação dos novos resultados obtidos a partir das etapas anteriores, assim, explicitado por Moraes (2003, p.191):

[...] a intensa impregnação nos materiais da análise desencadeada pelos dois estágios anteriores possibilita a emergência de uma compreensão renovada do todo. O investimento na comunicação dessa nova compreensão, assim como de sua crítica e validação, constituem o último elemento do ciclo de análise proposto. O metatexto resultante desse processo representa um esforço em explicitar a compreensão que se apresenta como produto de uma nova combinação dos elementos construídos ao longo dos passos anteriores.

O metatexto é a extensão da compreensão da problemática estudada e os resultados da construção do novo emergente desta pesquisa são apresentados e discutidos a seguir. 


\title{
3. RESULTADOS E DISCUSSÕES
}

A discussão envolvendo a geração de resíduos sólidos na Educação Escolar não pode prescindir da busca por precisar algumas definições importantes à compreensão da temática, como os termos 'reciclagem' e 'resíduos sólidos'. Eles encontram na Lei $\mathrm{n}^{\mathrm{o}}$ 12.305, de 02/08/2010, no seu Art. 3º, incisos XIV e XVI, respectivamente, a seguinte definição legal (BRASIL, 2010, p. 2-3):

\begin{abstract}
reciclagem: processo de transformação dos resíduos sólidos que envolve a alteração de suas propriedades físicas, físico-químicas ou biológicas, com vistas à transformação em insumos ou novos produtos, observadas as condições e os padrões estabelecidos pelos órgãos competentes do Sisnama e, se couber, do SNVS e do Suasa.

resíduos sólidos: material, substância, objeto ou bem descartado resultante de atividades humanas em sociedade, a cuja destinação final se procede, se propõe proceder ou se está obrigado a proceder, nos estados sólido ou semissólido, bem como gases contidos em recipientes e líquidos cujas particularidades tornem inviável o seu lançamento na rede pública de esgotos ou em corpos d’água, ou exijam para isso soluções técnica ou economicamente inviáveis em face da melhor tecnologia disponível.
\end{abstract}

Desse modo, um ponto de partida encontrado para a problematização da temática é contextualizá-la a partir dos contornos legais que a definem, isto é, com base nessa Lei $\mathrm{n}^{\circ} 12.305$ que instituiu a Política Nacional de Resíduos Sólidos - PNRS como mecanismo regulamentador da gestão de REEE. Tal estratégia pode conduzir à elaboração de indagações que estimulem a curiosidade, o senso crítico e engajamento social dos alunos, como explicitado na sequência.

Uma ideia perpassa pela aproximação da temática a situações vivenciadas no cotidiano familiar e/ou escolar do aluno, no qual, não raras vezes, ele convive desatento e/ou indiferente à presença de EEE em desuso, estragados, obsoletos e/ou que perderam sua funcionalidade. E, também, fica sujeito ao apelo comercial de publicidade capciosa e imperativa, que incita o consumo excessivo e irrefletido por parte de adolescentes e jovens, sem alertar para a preocupação que se deve ter com o descarte dos resíduos. $\mathrm{O}$ tema também é propício para evidenciar o papel da Educação Ambiental na formação cidadã e do pensamento crítico, bem como a relevância da constituição de políticas 
educacionais e marcos regulatórios para salvaguardar bens da coletividade e/ou garantir interesses comuns.

Ao conduzir esses aprendizados, convém trazer à tona aos alunos conceitos e concepções pertinentes à Educação Ambiental e suscitar a sua reflexão. Ou seja, pensar criticamente a partir de questionamentos que abarquem, por exemplo, as origens das problemáticas socioambientais associadas à sucata eletrônica, comumente designada 'lixo eletrônico'; os modos de produção, geração, consumo e descarte de produtos eletroeletrônicos. Nessa abordagem, sobressaem importantes conceitos a discutir: cultura e hábitos de consumo da sociedade contemporânea; 'Sistema de Logística Reversa'; 'obsolescência programada'; desinformação, atitudes irresponsáveis, insuficiência e/ou ineficácia da fiscalização com relação aos modos de descarte adequado do lixo eletrônico; distinção entre resíduo sólido e rejeito; origem e classificação do resíduo sólido do tipo lixo eletrônico; formas de tratamento dos REEE (em que se inclui a Reciclagem), entre outros.

De acordo com Xavier, Santos, Frade e Carvalho (2012), o ciclo de vida dos EEE tem início com a produção e sequência com as etapas de venda, consumo e descarte, quando é gerado o resíduo REEE. Esse ciclo finaliza com a destinação final, que pode ter como alternativas: a) a disposição final dos rejeitos em aterro sanitário (quando mais nenhum tipo de tratamento é possível submeter ao resíduo sólido), ou b) algum tipo de tratamento que permita o seu aproveitamento (mediante seu Reuso, reutilização) ou sua Reciclagem (processo que implica necessariamente na transformação do resíduo em insumos, nova matéria-prima ou novos produtos).

Apesar das intrincadas relações do assunto com o contexto societário global, no qual incidem inúmeras problemáticas socioambientais, os resultados evidenciam que o tema não tem assumido centralidade nas práticas educativas. A partir da análise do corpus, percebeu-se que são poucas as práticas de sala de aula abordando a temática da reciclagem de sucata eletrônica, no nível Médio do Ensino de Química para sensibilização ambiental dos alunos.

Tal constatação foi obtida com base na consulta às fontes de informação estudadas, nas quais foram recuperados quatro documentos pertinentes à temática. $\mathrm{O}$ material analisado, a partir da Pesquisa Bibliográfica, apresenta temas mais abrangentes tais como: 
preservação do meio ambiente; destinação correta do lixo eletrônico; legislação envolvida na Logística Reversa do Brasil e identificação de elementos químicos prejudiciais ao meio ambiente.

Percebeu-se também algumas recorrências quanto ao modo como a problemática lixo eletrônico está inserida na prática educativa. Constatou-se, em vários excertos, a preponderância de atividades como aulas teóricas, gincanas e palestras alusivas à Semana do Meio Ambiente. No entanto, elas se manifestam concebidas, de forma isolada, desarticuladas do ensino praticado em sala de aula e dos demais conteúdos do currículo e, portanto, sem ideia de a temática constituir-se como um tema gerador.

Para o professor melhor compreender e conduzir o trabalho educativo envolvendo os temas geradores (constituído a partir da consideração aos prévios conhecimentos que os educandos possuem), as reflexões sobre essa prática não podem prescindir da referência à obra de Paulo Freire (1921-1997). Cabe assinalar, como expõe Corazza (2003) que, especialmente, na publicação de 'Pedagogia do Oprimido', de 1969, é que Freire expôs, de modo mais sistematizado, o conceito de 'temas geradores'.

Esse resultado, oriundo da análise das publicações selecionadas, reflete a concepção tradicional de como o meio ambiente vem sendo trabalhado na Educação escolar. E indica uma carência quanto à abordagem tanto da reciclagem de sucata eletrônica, como tema gerador das práticas educativas, quanto das metodologias de ensino norteadoras do desenvolvimento dessas práticas nas aulas de Química.

Nos documentos analisados, aparece a ideia da importância de abordar a temática do lixo eletrônico para promover a sensibilização ambiental dos alunos. Contudo, Freire (1987) instiga o educador a ir além, aprofundando a discussão da temática, colocando em prática a concepção metodológica dialética. Corazza (2003, p.20) esclarece acerca desse paradigma epistemológico: "o dialético, que supõe partir da prática, teorizar sobre ela e voltar à prática para transformá-la”.

Nessa concepção, Freire defende, ainda, estimular que as soluções surjam no enfrentamento à realidade, em resposta ao desafio colocado pela proposição de certas contradições e tensões básicas, estruturalmente constituídas, as quais emergem, quando os temas são contextualizados, problematizados. Ou seja, a dialética surge diante da 
discussão do problema, pois as leituras de mundo ou representações e, principalmente, as tomadas de decisão dos sujeitos revelam-se diferentes; dialeticamente contradizem-se, perante o Universo temático, como discute Corazza (2003).

Nessa direção, entende-se que o professor pode conduzir os alunos a perceber as contradições e diferentes percepções em torno das criações oriundas da Ciência e da Tecnologia, ora posta como redentora, ora demonizada! Tal contexto é imperativo a que se reflita, no plano social e pedagógico, sobre como conduzir dialeticamente o desenvolvimento de práticas educativas em aula, a partir de um tema gerador.

Como resultado, também foram categorizadas como 'Estratégias Didáticas' duas possibilidades para abordagem da questão socioambiental nas práticas educativas, no nível médio do Ensino de Química: a) o uso de Experimentação na reciclagem com Placas de Circuito Impressas (PCIs) e na abordagem da questão socioambiental; b) o uso de Histórias em Quadrinhos (HQs) na reciclagem do lixo eletrônico. O engajamento de outros Componentes Curriculares a essas estratégias tende a ampliar o foco do tema gerador para tema transversal.

Entre os documentos relevantes apreciados, pode-se destacar a análise, por Silva (2019), de uma experiência bem sucedida envolvendo a reciclagem de Placas de Circuitos Impressos (PCI), cuja discussão envolveu alunos do $1^{\circ}$ ano do Ensino Médio no Estado de Fortaleza. Utilizando ferramenta de experimentação, professor e alunos constituíramse como sujeitos ativos na decodificação de conhecimentos sobre reações químicas, originadas de processos como a queima de gás GLP (Gás Liquefeito de Petróleo) e a ferrugem produzida em correntes de metal expostas ao ar livre.

Mediante exemplos de reações que estão presentes no cotidiano dos alunos, o processo de construção do ensino-aprendizagem deu-se a partir da comparação entre os resultados observáveis nas experimentações realizadas (sob a supervisão do professor) e a explanação teórica do conteúdo de reações. Ou seja, a fim de "contextualizar o conhecimento tomou-se como ponto de partida a extração, a reciclagem e os danos ambientais gerados do descarte de metais existentes nas PCI”' (SOUZA, 2019, p. 24). Esse mesmo autor, acrescenta ainda que para "mensurar o quanto a aprendizagem foi significativa para formulação dos conhecimentos" (SILVA, 2019, p. 24), o professor analisou a diferença, nas respostas dos alunos diante das abordagens inicial e final dos 
sujeitos da pesquisa, possibilitando captar suas percepções em relação ao conceito de reações químicas e à Educação Ambiental atrelados ao conteúdo.

Ao serem utilizados como estratégia didática, os experimentos com a reciclagem de PCI (material eletrônico descartado inicialmente de forma incorreta) demonstram o quanto podem trazer aprendizagens significativas aos alunos de Ensino Médio de Química. Tais recursos auxiliam-nos a compreender conteúdos de reações químicas, reciclagem e meio ambiente, tal como constatou Silva (2019, p. 25): “os dados provenientes dos questionários, composto de questões objetivas e subjetivas evidenciaram as percepções dos estudantes sobre práticas experimentais na fundamentação do conhecimento científico articulada pela teoria apresentada na aula".

Identificou-se ainda outra estratégia didática proeminente ao Ensino de Química, constituída pela abordagem da reciclagem do lixo eletrônico e da questão ambiental por meio de HQs, sobre a qual o estudo de Estevão (2017, p.4) tece a seguinte consideração: trata-se de "um campo de trabalho fértil, pois as HQs se configuram em um recurso de fácil acesso, com uma linguagem única". Nesse recurso, existe uma combinação de texto, imagem e conhecimentos que são mediados pelo uso da imaginação e criatividade como ações importantes para facilitar a compreensão e comunicação.

Embora, originalmente, não tenha sido realizada no Ensino Médio, mas aplicada a docentes e licenciandos em Química do IFRJ-CDUC, tal análise possui relevância por contemplar metodologias de ensino que podem conduzir ao desenvolvimento de práticas educativas em sala de aula. Estevão (2017, p. 96) aponta carências na utilização dessa metodologia no Ensino de Química no nível médio, conforme exposto a seguir:

\footnotetext{
Os trabalhos relatados referem-se ao ensino de Ciências como um todo, mas as experiências citadas podem ser utilizadas pelas mais diferentes áreas, inclusive no ensino de Química. Contudo, a utilização de HQs nessa área de conhecimento mostra-se incipiente, uma vez que um levantamento realizado, nas bases de dados Scientific Eletronic Library Online (Scielo); Revista Química Nova, Revista Ensaio - Pesquisa em Educação em Ciências; Revista Enseñanza de las Ciencias Naturales, demonstrou que não existem muitas publicações relacionando o ensino de Química, especificamente, com a utilização de HQs.
}

Os professores relacionaram a carência de HQs no Ensino de Química à não contemplação dessa metodologia na formação inicial dos futuros professores. Ou seja, sua aplicação no Ensino Médio pode ser reconhecida como uma prática pedagógica 
inovadora a que os professores de Química podem recorrer em suas aulas para envolver os alunos na construção coletiva de HQs, tornando-os mais participativos e protagonistas das histórias que almejam ver concretizadas em ações na sociedade.

A reflexão dos autores do corpus analisado reafirma a ideia de que a Química é uma ciência capaz de fazer o aluno perceber-se como cidadão na sociedade em que vive, com senso de pertencimento, portanto, ativo e responsável pelos seus atos. Essa ideia foi recorrente em vários núcleos de sentido, dos quais se destaca o trecho a seguir, a partir de Chassot (2004, p. 146 apud ESTEVÃO, 2017, p. 8):

[...] o ensino de Química para o cidadão deve estar centrado na interrelação de dois componentes básicos: a informação química e o contexto social, pois, para o cidadão participar da sociedade, ele precisa não só compreender a Química, mas também a sociedade em que está inserido. É da inter-relação entre esses dois aspectos que se vai propiciar ao indivíduo condições para o desenvolvimento da capacidade de participação, que lhe confere o caráter de cidadão.

Entende-se, pois, que essa estratégia didática responde aos objetivos iniciais do presente estudo, evidenciando que é factível a ideia de trabalhar a reciclagem de lixo eletrônico como tema gerador de aulas de Química, no nível médio do ensino. Portanto, avalia-se que a utilização de HQs como uma estratégia metodológica, somada a outras práticas como palestras e experimentos, envolvendo diretamente a reciclagem de lixo eletrônico com a questão ambiental, têm potencial para favorecer o aprendizado de conteúdos como reações químicas, por exemplo. As dificuldades de sua compreensão e principais causas de erros cometidos pelos alunos do ensino médio, estão associadas à fragmentação do ensino desses conteúdos e foram relacionadas por Meneses e Nuñes (2018, p. 176 apud SILVA, 2019, p.33), conforme é explicitado a seguir:

Uma das causas associadas aos erros dos estudantes na compreensão de uma reação química como sistema complexo está relacionada ao modo fragmentado e descontextualizado de se ensinar os conteúdos de química, sem estabelecer uma relação entre os próprios conteúdos da formação do conceito como também entre outros conteúdos e saberes que não estão relacionados com as vivências do dia a dia dos alunos, promovendo, assim, o ensino de uma ciência pouco significativa e, na maioria das vezes, difícil de ser realmente compreendida e aplicada pelos alunos. 
A análise de documentos apontando dificuldades por parte dos alunos do ensino médio para a compreensão de conteúdos em razão da sua fragmentação, são resultados que sinalizam a necessidade de a ação docente estar reeditando a concepção bancária da Educação (contexto esse vigente na década de 90, no qual se depositavam conteúdos ao invés de instaurar-se a prática do diálogo e o aprendizado, a partir dos conhecimentos prévios dos alunos). Nesse sentido, evidencia-se a Química como uma ciência complexa na qual ainda deve prevalecer, na Escola, o esforço para superar a condição apenas de memorização dos conceitos como objetivo de passar de ano e ingressar no Ensino Superior.

Pode-se constatar, então, que é necessário o empenho docente para viabilizar o encontro dos temas propostos às aulas com os valores, interesses e realidade dos alunos, a partir do diálogo. E, também, realizar a aplicação didática do método dialético por intermédio dos temas geradores, obtendo-se vários desdobramentos advindos dos questionamentos feitos, como elucidado a seguir.

A transição do campo teórico para o prático depende de uma aproximação do professor aos conhecimentos prévios dos alunos, sem desconsiderar o que é parte do contexto e interesse deles. É importante levar o indivíduo a perceber a Educação Científica conectada com as problemáticas locais e regionais para engajá-lo na discussão, permitindo desencadear novos conhecimentos. E, também, estimular a sua participação e envolvimento com situações e pessoas da comunidade, a fim de tornar o processo ensinoaprendizagem mais significativo.

Nesse sentido, é pertinente a discussão envolvendo o custo da coleta seletiva dos REEE, por exemplo. E levantar questionamentos acerca das dificuldades e razões pelas quais os municípios de pequeno porte, em geral, não dispõem de programas de coleta seletiva, evidenciando o custo financeiro e a capacidade técnica de gestão que esse processo socioambiental representa para órgão municipal competente.

Assim, é oportuno problematizar questões político-educacionais implicadas nisso, as quais levam as autoridades locais a não priorizar projetos voltados à obtenção de resultados de médio e longo prazo (por razões como tempo de gestão do governo, decisões partidárias e resultados não perceptíveis associados ao grau de instrução e participação 
da população). Tal estratégia possibilita ao professor dar abertura a outros debates acerca de interesses políticos, gestão e orçamento público, por exemplo.

Nessa direção, é importante atentar para que a temática não venha a "ficar particularizada a um grupo social, mas estar sempre referida às relações que tem com os temas históricos do contexto societário global”, como sugere Corazza (2003, p.21).

Sobretudo, avalia-se que, na abordagem da questão socioambiental, as estratégias didáticas categorizadas neste trabalho - tais como o uso de Experimentação e de Histórias em Quadrinhos - podem ampliar a compreensão do sujeito acerca da realidade em que vive e que precisa enfrentar, com postura de decisão, como destacado no pensamento freireano. Essa Educação que se pretende conscientizadora e dialógica (pautada no respeito mútuo), também pode transformar a realidade de municípios como Caibaté/RS, utilizando a reciclagem de PCI e HQs como práticas na execução do tema gerador.

\section{CONSIDERAÇÕES FINAIS}

A conscientização, quanto ao agravamento dos problemas socioambientais associados ao lixo eletrônico, demanda que o professor provoque/suscite maior reflexão e senso crítico dos alunos em relação aos seus atos cotidianos, do consumir desenfreado, cumulativo e além do necessário. Sobretudo, alertá-los para a apreensão dos motivos que subjazem à produção desenfreada, aos estímulos midiáticos que apelam ao consumo excessivo e à obsolescência programada. A temática não pode prescindir da discussão sobre o processo de geração, descarte e reciclagem desse 'resíduo perigoso'.

A partir da Educação ambiental, no processo de 'ensinar e aprender', a discussão do tema 'reciclagem de sucata eletrônica' pode ser introduzida pela sua proximidade com a realidade concreta da vida dos sujeitos, da qual não convém que seja desvinculada pelos inúmeros desdobramentos possíveis no ensino (apontados na seção anterior), que constituem a sua problematização. Tal estratégia oportuniza profícuos aprendizados aos alunos, promovendo a formação cidadã, o pensamento crítico e criativo. Pressupostos esses que dirigem o aluno a pensar, posicionar-se, colocando em suspenso dogmas e verdades pré-estabelecidos, capacitando-o não apenas para acessar a informação, mas para refletir sobre ela de forma científica. 
Com relação à problemática socioambiental, entre os agravantes, repercutem o desconhecimento e pouco empenho para criação, aperfeiçoamento e/ou implantação de práticas que possam minimizar o impacto ambiental produzido pela sociedade do século XXI e, ainda, contribuir para redução do volume de resíduos gerados. Desde a Escola, importa que o professor oriente o estudo de conceitos relevantes e promova debates, buscando explicações a partir dos resultados de pesquisas científicas, das práticas de experimentação e dos relatos de experiências já desenvolvidas.

Nesse sentido, destaca-se a importância do registro das experiências de ensinoaprendizagem bem sucedidas, nas quais a elaboração de uma compreensão a seu respeito também se constitui dialeticamente porque, afinal, os resultados exitosos são sugestivos à reflexão de outros que são seus contrários, oriundos de leituras de mundo e tomadas de decisão diferentes, diante do mesmo problema.

Revela-se, assim, a preocupação com a apropriação de conhecimentos que forneçam aos educandos informações para que eles estejam capacitados a enfrentar a realidade, de forma crítica, e exercitar sua cidadania por meio da compreensão, interpretação e análise dos problemas que fazem parte do seu entorno social. E, dessa forma, discutir-se com os alunos sobre as distintas soluções possíveis, relativas aos processos de aproveitamento e/ou de reciclagem de resíduos sólidos.

Diante dos prejuízos ambientais e à saúde humana, inerentes ao descarte irresponsável de EEE na sociedade contemporânea, compete à Educação capacitar os alunos para a discussão crítica sobre a reciclagem usando esses resíduos com fins de produzir novos materiais, transformando-os em outros produtos, com base nos conhecimentos que são apropriados a partir do Ensino de Química.

Nesse sentido, ressalta-se a importância da atuação docente incidindo no processo de ensinar e aprender Química, despertando a curiosidade dos alunos do Ensino Médio, encorajando-os a desenvolver experiências intrincadas à sua realidade e a propor ações para minimização dos REEE, sensibilizando-os para questões socioambientais que interessam à coletividade em discuti-las e problematizá-las por meio da Educação Ambiental. Com isso, tem-se a expectativa de que, no percurso formativo do aluno na Escola, a Educação Ambiental possa conduzi-lo a perceber que seus atos individuais 
somam-se às atitudes das demais pessoas. E, assim, o descarte incorreto pode agravar a problemática socioambiental.

Nessas ações, é que se manifesta o papel da Escola, da sua proposta de formação e do modelo de conhecimento que são aplicados à prática pedagógica. Reflete-se a partir da concepção freireana que, no ofício de ensinar, importa focar-se não em transferir conhecimentos em aula, mas em criar oportunidades para sua produção e transformação. E, assim, proporcionar o desenvolvimento das várias competências (socioemocionais, socioafetivas, cognitivas, mentais) e habilidades do aluno do século XXI.

É importante pensar nas estratégias e condições para que o professor esteja em formação continuada e possa ampliar sua bagagem cultural e seu repertório de saberes, também no campo didático-pedagógico e dos fundamentos de natureza epistemológica e metodológica. Tal aporte o instrumentaliza e auxilia no desempenho exitoso da sua tarefa, qual seja: planejar situações para que o aluno consiga aprender as diferentes abordagens conceituais, a partir de situações-problema; do confrontamento de ideias oriundas dos distintos tipos de conhecimento (do senso comum e do conhecimento científico, sistematizado).

A proposta metodológica freireana desafia os professores à reflexão-ação em torno de questões inquietantes que afetam a sociedade contemporânea e cuja discussão encontra-se alinhada aos pressupostos CTS. Sua abertura ao diálogo, ao relato de experiências e ao espelhamento de práticas inovadoras pode instigar o professor a (re)pensar acerca do ensinar e do aprender. Isso contribui para formação de cidadãos comprometidos com a questão socioambiental, ensejando, assim, uma Educação transformadora.

Essa atual conjuntura é desafiadora ao cumprimento dos propósitos da Educação para todos e multialfabetizadora. E, oportunamente, pode ser aproximada à realidade dos alunos a fim de ressignificar os seus aprendizados, bem como os conhecimentos prévios e do senso comum, sem desconsiderá-los; desenvolver o pensamento crítico e criativo (acessar informações, sabendo refletir criticamente e de forma científica a seu respeito); enfim, desenvolver as múltiplas habilidades e competências requeridas do aluno do século XXI para torná-lo capacitado a aprender a aprender. 


\section{REFERÊNCIAS}

BRASIL. Lei no 12.305, de 2 de Agosto de 2010. Institui a Política Nacional de Resíduos Sólidos - PNRS; altera a Lei no 9.605, de 12 de fevereiro de 1998. Brasília: Presidência da República. Casa Civil. Subchefia para Assuntos Jurídicos, 2010. Disponível em: http://www.planalto.gov.br/ccivil_03/_ato20072010/2010/lei/112305.htm. Acesso em: 25 jul. 2020.

BRASIL. Resolução CNE/CP n 2, de 15 de junho de 2012. Estabelece as Diretrizes Curriculares Nacionais para a Educação Ambiental. Brasília: Ministério da Educação, 2012. Disponível em: http://portal.mec.gov.br/mais-educacao/323-secretarias112877938/orgaos-vinculados-82187207/17810-2012-sp-1258713622. Acesso em: 18 set. 2020.

CORAZZA, S. M. Tema gerador: concepção e prática. 3. ed. Ijuí: Ed. Unijuí, 2003.

ESTEVÃO, A. P. S. da S. História em quadrinhos no ensino de Química como estratégia didática para abordagem do tema "lixo eletrônico". 2017. Tese (Doutorado em Ensino em Biociências e Saúde) - Instituto Oswaldo Cruz, Fundação Oswaldo Cruz, Rio de Janeiro, 2017. Disponível em: https://www.arca.fiocruz.br/handle/icict/26323. Acesso em: 23 de jun. 2020.

FREIRE, P. Pedagogia do Oprimido. 17. ed. Rio de Janeiro: Paz e Terra, 1987.

GIL, A. C. Como elaborar projetos de pesquisa. 4. ed. São Paulo: Atlas, 2002.

GIL, A. C. Métodos e técnicas de pesquisa social. 6. ed. São Paulo: Atlas, 2008.

IBGE. Cidades e Estados: Caibaté, 2019. Disponível em:

https://cidades.ibge.gov.br/brasil/rs/caibate/panorama. Acesso em: 9 jun. 2020.

INEP. Thesaurus brasileiro de Educação. Disponível em:

http://pergamum.inep.gov.br/pergamum/biblioteca/pesquisa thesauro.php. Acesso em: 16 jun. 2020.

MORAES, R. Uma tempestade de luz: a compreensão possibilitada pela análise textual discursiva. Ciência \& Educação, v. 9, n. 2, p. 191-211, 2003. Disponível em: https://www.scielo.br/pdf/ciedu/v9n2/04.pdf?fbclid=IwAR0hpVncDL7sgJyu1SywD7kg afeu5LkDnWFw-6sdop-lwhzdk3_hG3OQTtQ. Acesso em: 15 jun. 2020.

MORAES, R.; GALIAZZI, M. C. Análise textual discursiva. Ijuí: Editora Unijuí, 2007. 
SILVA, J. de A. de S. Contextualização do ensino de reações químicas através da reciclagem de placas de circuitos impressos. 2019. Trabalho de Conclusão de Curso (Licenciatura em Química) - Centro de Ciências, Universidade Federal do Ceará, Fortaleza, 2019. Disponível em:

file:///C:/Users/vanda/OneDrive/Documentos/MESTRADO/Artigo\%20Prof.\%20Patr\% C3\%ADcia/Artigos\%20indicados/5.\%20quimica\%201\%C2\%BA\%20ano\%20rea\%C3\% A7\%C3\%B5es.pdf . Acesso em: 24 jun. 2020.

SOUSA, R. S. de; GALIAZZI, M. do C. O jogo da compreensão na Análise Textual Discursiva em pesquisas na Educação em Ciências: revisitando quebra-cabeças e mosaicos. Ciênc. Educ., Bauru, v. 24, n. 3, p. 799-814. 2018. DOI: https://doi.org/10.1590/1516-731320180030016. Disponível em: https://www.scielo.br/pdf/ciedu/v24n3/1516-7313-ciedu-24-03-0799.pdf. Acesso em: 15 jun. 2020.

\section{UNIVERSIDADE DE SÃO PAULO. Vocabulário Controlado do SIBi/USP.}

Disponível em: http://vocabusp.sibi.usp.br/vocab/. Acesso em: 29 maio 2020.

XAVIER, L. H.; SANTOS, M. C. L. dos; FRADE, N. B.; CARVALHO, T. C. M. de B. (Org.). Aspectos socioambientais e técnicos da Gestão de Resíduos de Equipamentos Eletrônicos. São Paulo: IEE-USP, 2012. Disponível em: http://www.iee.usp.br/?q=pt-br/publicacao-iee/aspectos-socioambientais-et\%C3\%A9cnicos-da-gest\%C3\%A3o-de-res\%C3\%ADduos-de-equipamentoseletr\%C3\%B4nicos. Acesso em: 10 jul. 2020. 